Wright State University

CORE Scholar

$9-2008$

\title{
Shifts in Southern Wisconsin Forest Canopy and Understory Richness, Composition, and Heterogeneity
}

\author{
David A. Rogers \\ Thomas P. Rooney \\ Wright State University - Main Campus, thomas.rooney@wright.edu \\ Daniel Olson \\ Donald M. Waller
}

Follow this and additional works at: https://corescholar.libraries.wright.edu/biology

Part of the Biology Commons, Medical Sciences Commons, and the Systems Biology Commons

\footnotetext{
Repository Citation

Rogers, D. A., Rooney, T. P., Olson, D., \& Waller, D. M. (2008). Shifts in Southern Wisconsin Forest Canopy and Understory Richness, Composition, and Heterogeneity. Ecology, 89 (9), 2482-2492.

https://corescholar.libraries.wright.edu/biology/75

This Article is brought to you for free and open access by the Biological Sciences at CORE Scholar. It has been accepted for inclusion in Biological Sciences Faculty Publications by an authorized administrator of CORE Scholar. For more information, please contact library-corescholar@wright.edu.
} 


\title{
SHIFTS IN SOUTHERN WISCONSIN FOREST CANOPY AND UNDERSTORY RICHNESS, COMPOSITION, AND HETEROGENEITY
}

\author{
David A. Rogers, ${ }^{1}$ Thomas P. Rooney, ${ }^{2}$ Daniel Olson, ${ }^{1}$ and Donald M. Waller ${ }^{1,3}$ \\ ${ }^{1}$ Department of Botany, University of Wisconsin-Madison, 430 Lincoln Drive, Madison, Wisconsin 53706 USA \\ ${ }^{2}$ Department of Biological Sciences, 236 BH, Wright State University, 3640 Colonel Glenn Highway, Dayton, Ohio 45435 USA
}

\begin{abstract}
We resurveyed the under- and overstory species composition of 94 upland forest stands in southern Wisconsin in 2002-2004 to assess shifts in canopy and understory richness, composition, and heterogeneity relative to the original surveys in 1949-1950. The canopy has shifted from mostly oaks (Quercus spp.) toward more mesic and shade-tolerant trees (primarily Acer spp.). Oak-dominated early-successional stands and those on coarse, nutrient-poor soils changed the most in canopy composition. Understories at most sites (80\%) lost native species, with mean species density declining $25 \%$ at the $1-\mathrm{m}^{2}$ scale and $23.1 \%$ at the $20-\mathrm{m}^{2}$ scale. Woody species have increased $15 \%$ relative to herbaceous species in the understory despite declining in absolute abundance. Initial canopy composition, particularly the abundance of red oaks (Quercus rubra and Q. velutina), predicted understory changes better than the changes observed in the overstory. Overall rates of native species loss were greater in later-successional stands, a pattern driven by differential immigration rather than differential extirpation. However, understory species initially found in early-successional habitats declined the most, particularly remnant savanna taxa with narrow or thick leaves. These losses have yet to be offset by compensating increases in native shade-adapted species. Exotic species have proliferated in prevalence (from 13 to 76 stands) and relative abundance (from $1.2 \%$ to $8.4 \%$ ), but these increases appear unrelated to the declines in native species richness and heterogeneity observed. Although canopy succession has clearly influenced shifts in understory composition and diversity, the magnitude of native species declines and failure to recruit more shade-adapted species suggest that other factors now act to limit the richness, heterogeneity, and composition of these communities.
\end{abstract}

Key words: biotic homogenization; oak forest; shade tolerance; species loss; succession; understory.

\section{INTRODUCTION}

At the time of European settlement, southern Wisconsin was a patchy mosaic of woodland and prairie, with a predominance of oak savanna (Curtis 1959) likely maintained by fires (Dorney 1981). Forests occurred where natural firebreaks (Leitner 1991) and moist microclimates favored trees (Kline and Cottam 1979). Following European settlement, fire suppression allowed oak forests to establish more broadly (Gleason 1922, Cottam 1949). Work by Cottam (1949), Larsen (1953), and McIntosh (1957) led Curtis (1959) to generalize that without fire or other disturbance, oak would remain dominant for only a single generation, except on xeric sites. Since then, oak forests have declined across much of eastern and Midwestern North America, with oaks being replaced by shade-tolerant trees in the canopy and the understory (Peet and Loucks 1977, McCune and Cottam 1985, Rentch and Hicks 2005). These shifts alter the light environment (Fralish 1997), favoring plants with adaptations to shade

Manuscript received 9 July 2007; revised 15 January 2008; accepted 24 January 2008. Corresponding Editor (ad hoc): S. G. Pallardy.

${ }^{3}$ Corresponding author. E-mail: dmwaller@wisc.edu
(Givnish 1987). These declines in oak abundance support the view that fire suppression, succession, pests, and pathogens have all acted to diminish oak dominance (Abrams 1992, 2003, 2005, Abrams and Nowacki 1992, Lorimer 1993, 2003, Fralish 2004). Simultaneous expansions of agriculture and development also reduced many of these forests to smaller and more isolated patches (Sharpe et al. 1987, Radeloff et al. 2005).

Although the expansion of maples and other shadetolerant, mesic species in forests previously dominated by oaks is well documented (Shotola et al. 1992, Fralish 2004, Ozier et al. 2006, Spyreas and Matthews 2006), it is not clear how this trend is influencing the structure, dynamics, or composition of the forest understory. Although shrubs and herbaceous plants often receive less attention from researchers than trees, the forest understory is of particular interest, as this layer supports most of the plant diversity present in temperate forests and provides critical resources for game animals like white-tailed deer (Odocoileus virginianus) and Wild Turkey (Meleagris gallopavo), as well as insect pollinators, predatory arthropods, and parasitoids that provide critical ecosystem services (Landis et al. 2000, Westerkamp and Gottsberger 2000).

We often lack baseline data for assessing changes in the composition of understory communities, especially 
at larger spatial scales. Here, we transcend this limitation by accessing the high-quality data collected by the University of Wisconsin Plant Ecology Laboratory (PEL) half a century ago. The PEL surveyed the vegetation at $>1000$ sites across Wisconsin in the 1940s and 1950s, providing a quantitative description of the state's plant communities summarized in The Vegetation of Wisconsin (Curtis 1959). Because the data were carefully archived, the same stands could be relocated and sampled to measure changes in these plant communities over time. These surveys have proved useful for analyzing long-term (40-55 year) ecological changes in remnant prairies (Leach and Givnish 1996, Milbauer and Leach 2007) and upland forests in northern Wisconsin (Rooney et al. 2004a, $b$, Wiegmann and Waller 2006). Studies so far have revealed major shifts in community composition, even at less disturbed and formally protected sites.

Here, we report changes occurring over the last 50+ years in 94 upland forest stands distributed across southern Wisconsin (Curtis and McIntosh 1951, Whitford and Saluman 1954). We expected greater rates of understory species losses and community homogenization in southern forests than those observed in northern forests (Rooney et al. 2004b), as southern forests have been more broadly affected by fire suppression, habitat fragmentation, and development (Sharpe et al. 1987, Fralish 1997, Radeloff et al. 2005). Our goal was to characterize the nature and rate of changes that have occurred in southern Wisconsin upland forests, emphasizing changes in oak dominance and the coincident changes in the forest understory. Here we report changes within sites in species richness and composition as well as shifts in patterns of heterogeneity among sites. We focus on how changes in species richness and composition in each layer reflect site and forest conditions at the time of the PEL survey, and links between changes in the overstory and understory. Because succession is an important factor driving ecological change in southern Wisconsin forests (Cottam 1949, Curtis 1959, Peet and Loucks 1977, Lorimer 2003), we expected changes in understory community composition to be strongly linked with shifts in canopy conditions. We also expected understory communities to be undergoing biotic homogenization (McKinney and Lockwood 1999, Olden and Poff 2003), as shade-tolerant, latesuccessional understory species replace more lightdemanding species (Cottam 1949, Bray 1958, Reid 1964). We are currently investigating how surrounding landscape conditions affect understory dynamics and invasions of exotic plants in these forests.

\section{Methods}

\section{Study area}

Our study sites were distributed throughout Southern Wisconsin in the prairie-forest transition zone of the Eastern Deciduous Forest Province (Albert 1995: Fig. 1). Elevation ranges from 177 to $488 \mathrm{~m}$ above sea level

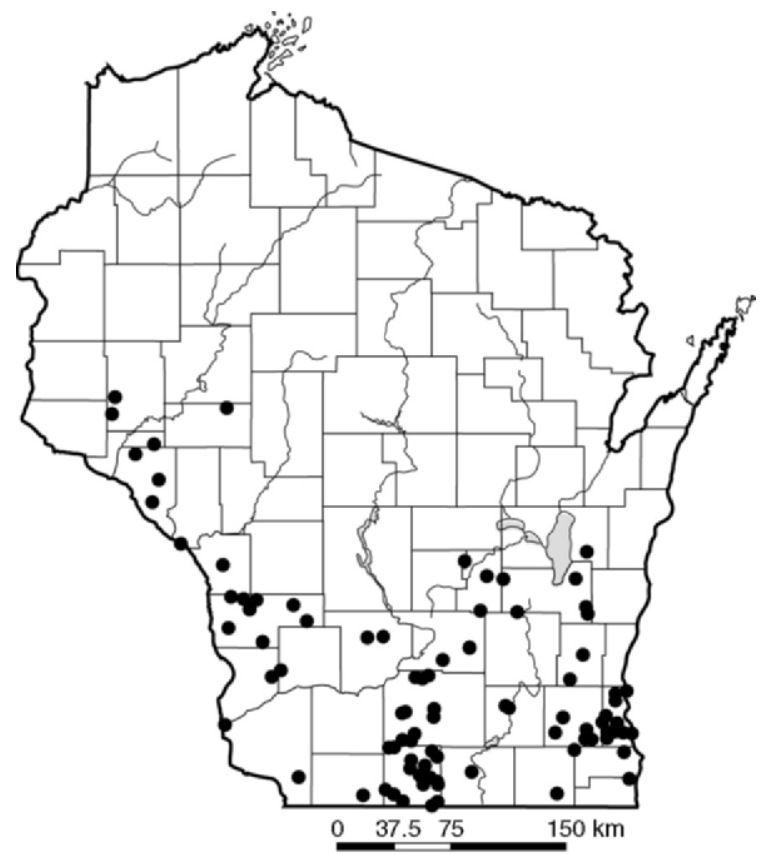

FIG. 1. Map of the 94 study sites (shown as black circles) in southern Wisconsin.

and the climate is continental, with precipitation ranging from 61 to $84 \mathrm{~cm}$ from west to east. Topography varies between the glaciated region to the east dominated by glacial till plains, moraines, drumlins, and outwash plains, and the unglaciated "driftless" area to the west, a highly dissected upland of Ordovician origin with agriculture on most valley bottoms and many forested slopes. The unglaciated western region also has lower population and road densities than the eastern glaciated region (Radeloff et al. 2005). We generally expected early-successional stands to retain more species, as richness often peaks in middle phases of forest succession, with oak woodland supporting both shadetolerant and shade-intolerant species (Loucks 1970, Auclair and Goff 1971).

\section{Site selection and vegetation sampling}

In the original survey, the PEL sampled the composition, density, and dominance of canopy trees generally using the random pairs method (Cottam and Curtis 1956) at 40 points spaced evenly $15-20 \mathrm{~m}$ apart along a square-shaped transect located at least $30 \mathrm{~m}$ from the forest edge. At 20 of these 40 points, they recorded the presence/absence of all herb, shrub, vine, and tree seedling species in $1-\mathrm{m}^{2}$ quadrats. They also compiled a "walk-through" list of all vascular plants for each site.

We resampled all sites that retained their tree canopy except for residential yards, tree plantations, and stands used for pasture. We included forest patches that occurred in partly residential areas if they were undeveloped and $>6$ ha. Of the 114 original PEL sites with quantitative data, 16 sites $(14 \%)$ were highly 
degraded or lost to residential or commercial use (14 sites), cattle grazing (1 site), or cropland (1 site). We were refused access to four sites. We resurveyed the remaining 94 stands (Fig. 1) in 2002-2004 (henceforth "2004") using identical but more intensive methods. We chose to retain the original methods to avoid bias due to changes in sampling scheme and to allow for direct methodological comparisons with earlier results.

Working from the original hand-drawn maps and site descriptions, we relocated each stand and sampled the area within the stand that was most similar to the original description in terms of slope, topography, and canopy composition. To account for uncertainty in the exact location of the original survey and test for variability in observed trends, we replicated canopy sampling two times (160 trees per site) and sampled the understory at 80 (instead of 20) points. Replicates were placed within homogenous portions of the stand and, when necessary, stratified by disturbance history. Replicate No. 1 was assigned to the location that best matched the stand originally described. We also noted any evidence for and the estimated intensity of past logging activity based on the density of stumps.

We collected soil samples from 10 randomly dispersed points within each site, sampling at least $300 \mathrm{~cm}^{3}$ from the top $10 \mathrm{~cm}$ of soil. These samples were pooled and refrigerated until they were analyzed by the University of Wisconsin Soil and Plant Analysis Laboratory for soil texture (percentage of sand, silt, and clay) and constituents (percentage of organic matter, $\mathrm{pH}$, and percentage of total nitrogen, phosphorus, potassium, calcium, and magnesium). We assumed that soil texture in 2004 reflected the texture it had in 1950, but note that changes in vegetation and litter may have caused some changes (Van Breemen and Finzi 1998). Principal components analysis of the soil variables returned a three-dimensional solution explaining $80.2 \%$ of the variance. The first principal component (PC1) mostly reflected fertility $(\mathrm{pH}, \%$ organic matter, percentage of $\mathrm{N}$, and parts per million of $\mathrm{Ca}$ and $\mathrm{Mg}$ ), and explained $50 \%$ of the variance. PC2 mostly reflected soil texture (percentage of sand and silt) and explained an additional 19\% of the variance. PC3 correlated strongly with percentage of clay and soil $\mathrm{P}$ concentrations and explained an additional $10 \%$ of the variance. We use these extracted principal components to represent variation in soil conditions across sites.

\section{Taxon and sampling standardization}

We identified all taxa to species using keys from Gleason and Cronquist (1991). Any plant not positively identified in the field was collected and later identified by specialists (voucher specimens on deposit at the University of Wisconsin Herbarium). From the original PEL field data, we compiled a full species list, translating the various names, abbreviations, and codes used in the original data to current nomenclature (University of Wisconsin Herbarium). In some cases, the PEL lumped what are now recognized as distinct species, split taxa that are now combined, or applied inconsistent taxonomic resolution between observers. When necessary, we combined taxa into the next highest taxonomic group (e.g., Carex spp). To assess the effects of these decisions, we compared estimates of key response variables (e.g., species loss and biotic homogenization) at different levels of taxonomic resolution, and found that although point estimates of the amount of species loss and homogenization shift with variation in taxonomic resolution, the relationships of these response variables to various predictor variables remain qualitatively and quantitatively similar (Rogers 2006).

Because sample sizes were several times higher in 2004 than in 1950, we standardized the sample size for the understory to $201-\mathrm{m}^{2}$ quadrats, and standardized tree samples to 80 individuals, matching sample sizes in 1950 . Because estimates of species richness, composition, and heterogeneity between replicates were highly correlated and related similarly to the predictor variables (Rogers 2006), we only report here the results from the first replicate.

\section{Analyses}

We estimated tree density (stems per hectare), average basal area, and total basal area per hectare for each stand in each time period from the random pairs data (Cottam and Curtis 1949, 1956). We then assessed changes in density and basal area using a paired $t$ test. To assess the effects of initial canopy composition and succession, we used the "successional adaptation values" (SAV) developed by Peet and Loucks (1977) for southern Wisconsin forest trees. Peet and Loucks applied principal components analysis on tree size class data (from 30 of these original PEL sites) to rank canopy species from 1 to 10 , according to their increasing dominance in smaller size classes, reflecting their ability to survive in late-successional stands. For each site, we computed a Successional Index (SI) value in each time period by averaging the SAV values for all trees present at each site, weighted by their relative abundance. Because oaks are a keystone species in this system, we also calculated declines in abundance and dominance for all Quercus species. Finally, as a direct measure of shifts in canopy composition, we calculated overstory stability as the compositional similarity of each site to itself 55 years later using the Bray-Curtis similarity metric.

We compared estimates of canopy species richness per stand between the two time periods using a paired $t$ test. For each species in each stand, we tallied abundance (number of stems observed), relative abundance, average basal area per stem, and relative basal area ([abundance $\times$ average basal area]/total basal area). We then used $G$ tests to determine whether individual species increased or decreased through time across all sites.

In the understory, we compared richness at several spatial scales, starting with the regional species pool. We 
used paired $t$ tests to compare diversity of all native understory species (herbs, shrubs, and woody vines) at the $1-\mathrm{m}^{2}$ and $20-\mathrm{m}^{2}$ scales, comparing the means across all quads in the 1950 sample with those in the resample. We then analyzed herbaceous and woody species separately, again using paired $t$ tests to analyze shifts in richness. We used these data to compute rates of change in species richness between the two sample periods using the formula $N_{2000}=\lambda\left(N_{1950}\right)$, where $N$ is the number of species present at the site and $\ln (\lambda)$ is the rate of change (equivalent to a log response ratio [Osenberg et al. 1997]). We added 0.1 to both the numerator and denominator to avoid dividing by zero.

To characterize species dynamics, we estimated extirpation and colonization rates from the samples, noting the number of native species apparently lost or gained at each site. Rates of extirpation and colonization were then calculated as the number of native species lost divided by the native species richness in 1950, and the number of native species gained relative to native richness in 2004, respectively.

To evaluate overall shifts in community composition and assess which species were most sensitive to change, we used several multivariate approaches. For each stand and time period, we calculated the mean similarity in species composition to the other 93 stands using the Bray-Curtis measure of similarity (McCune and Grace 2002). We analyzed changes in average similarity using a paired $t$ test, considering stands to have undergone biotic homogenization if average similarity increased between 1950 and 2004. We estimated rates of homogenization within stands using the formula given above.

To identify which species contribute the most to the differences in community richness and heterogeneity between sample periods, we applied nonmetric multidimensional scaling (NMDS) ordination to the combined data sets (both 1950 and 2004 analyzed together). This generates a set of orthogonal synthetic axes for plotting sites in species space where proximity reflects floristic similarity. To test for differences in species composition and community structure between time periods, we used ANOSIM (Clarke 1993), a nonparametric permutation procedure that tests the hypothesis that no difference exists between sample periods in terms of community composition. We then examined the relative importance of individual species in each time period by using the SIMPER routine in Primer 5 (Clarke 1993). We use these procedures to first test whether species composition has shifted in a consistent manner between sample periods, and second, to describe the importance value of individual species in the "average" stand in each time period. As with changes in richness and heterogeneity, we perform separate analyses on canopy composition, the overall understory community, and the herbaceous and woody components of the understory community.

To examine the influence of exotic species, we assessed how changes in native species richness and community heterogeneity responded to: (1) the number of invasive exotic species present in the stand in 2004 , (2) the total frequency of all exotics at that site, and (3) the relative frequency (dominance) of invasive exotics at the site.

To predict changes in the overstory and understory communities, we examined how the computed rates of change in species richness and community similarity depend on initial canopy composition (SI), changes in canopy composition, and change in stand basal area. We used forward stepwise multiple regressions to identify which combinations of these variables best explained changes in species richness and average compositional similarity. Finally, we applied a randomization (Mantel) test with 5000 permutations to examine the correlation between overstory and understory composition in each time period.

\section{RESULTS \\ Canopy changes}

Overall tree density decreased $\sim 16 \%$, (from 380 to 318 trees/ha; paired $t=4.52, P<0.0001, n=94$ for this and all following analyses). Over the same period, mean basal area of trees remained roughly steady, increasing $5 \%$, (from 716 to $751 \mathrm{~cm}^{2}$, paired $t=1.11, P=0.32$ ). These changes account for a $10 \%$ decrease in estimated stand basal area per hectare (from 25.7 to $23.1 \mathrm{~m}^{2} /$ ha, paired $t=2.17, P=0.02$ ).

Average canopy species richness increased $19 \%$, (from 8.4 to 10.0 species per site, paired $t=-4.93, P<0.001)$. This increase in within-site species richness was accompanied by a $14 \%$ divergence in overstory Bray-Curtis similarity among sites (from 36.9 to 31.8 , paired $t=6.99$, $P<0.0001)$. Neither logging history nor logging intensity significantly affected changes in species richness or heterogeneity.

The abundance and dominance of Quercus has declined significantly since the original survey, while mid- and late-successional taxa (based on SAV values) including Acer saccharum, A. rubrum, Carya cordiformis, Ulmus spp., and Prunus serotina have increased (Fig. 2). Species in the red oak group (Quercus rubra and $Q$. velutina) experienced greater declines in importance (48.6\% and $47.1 \%$ ) than Quercus alba (31.1\%). The diameter distribution of Quercus spp. has also shifted from an approximate reverse-J distribution characteristic of expanding populations to a distribution characteristic of senescent populations (Fig. 3A), increasing the mean basal area per oak. In contrast, populations of Acer spp. have maintained and expanded their vigorous reverse-J diameter distributions (Fig. 3B). Changes in the succession index (SI) (Peet and Loucks 1977) support these trends. Average stand SI increased by $33 \%$ (from 4.52 to 6.07 , paired $t=-11.57, P<0.0001$ ), reflecting increased dominance by later successional species.

The NMDS analysis also suggests that canopy composition has shifted since 1950 (Fig. 4A). ANOSIM analysis revealed significant differences in ordination space between the two sample periods (global $R=0.093$, 


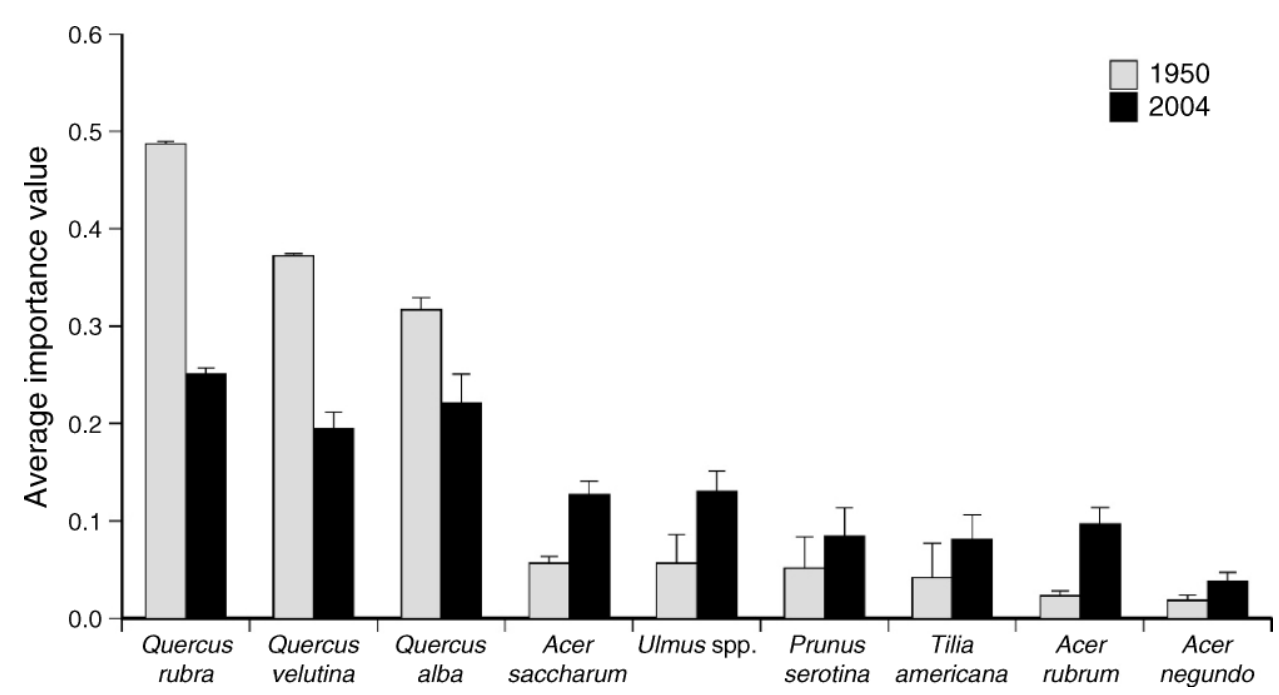

FIG. 2. Changes in the relative abundance of major canopy species. Species are ranked in decreasing abundance based on the original sample data (see Methods). Error bars represent + SE.

$\alpha=0.1 \%$ with no permutations out of $1000>$ global $R$ ). This supports the idea that the 1950 and 2004 samples represent distinct "groups" (i.e., that community composition has shifted). Analyses of the relative importance of species in each sample group (1950 vs. 2004) provided a clear picture of species changes at the community level (Appendix A). In the 1950 sample, only six species account for $>90 \%$ of the total variation in the species $\times$ site data matrix, whereas it took nine species to explain this much variation in the 2004 sample. Moreover, species dominance among the top four species reversed. In the 1950 sample group, the average stand was dominated by Quercus rubra and Quercus alba, with a combined importance value of $59.2 \%$. The importance of these oaks declined $>50 \%$ (to $26.3 \%$ ) by 2004, while the combined importance value of more mesic species (Acer saccharum and Tilia americana) more than doubled (from $18.9 \%$ to $37.6 \%$ ).

\section{Changes in the understory}

Across the 94 sites, Curtis and colleagues detected 220 native taxa in 1950. Of these, 64 did not appear in the resample. We detected an additional 33 native species for a total of 189 native species in the 2004 sample. Thus, we observed a $15 \%$ decrease in the number of native species present in the regional species pool. In contrast, the regional pool of exotic species more than doubled from 13 species $(5.5 \%)$ in 1950 to 31 species
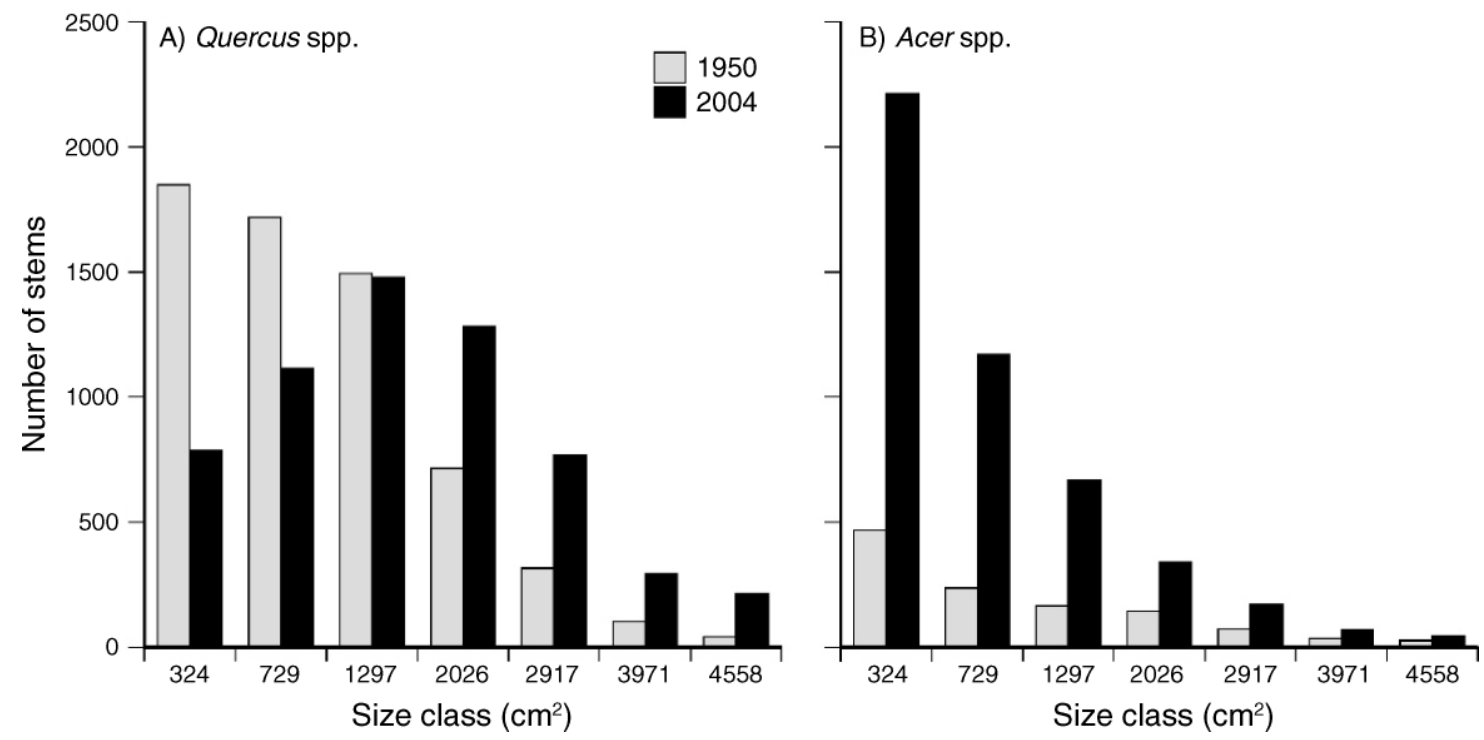

FIG. 3. Changes in the size class distributions of (A) oak and (B) maple tree stems between ca. 1950 and 2004 across all 94 sites. Bars show the number of stems occurring within each size class (defined as the maximum basal area per tree). 

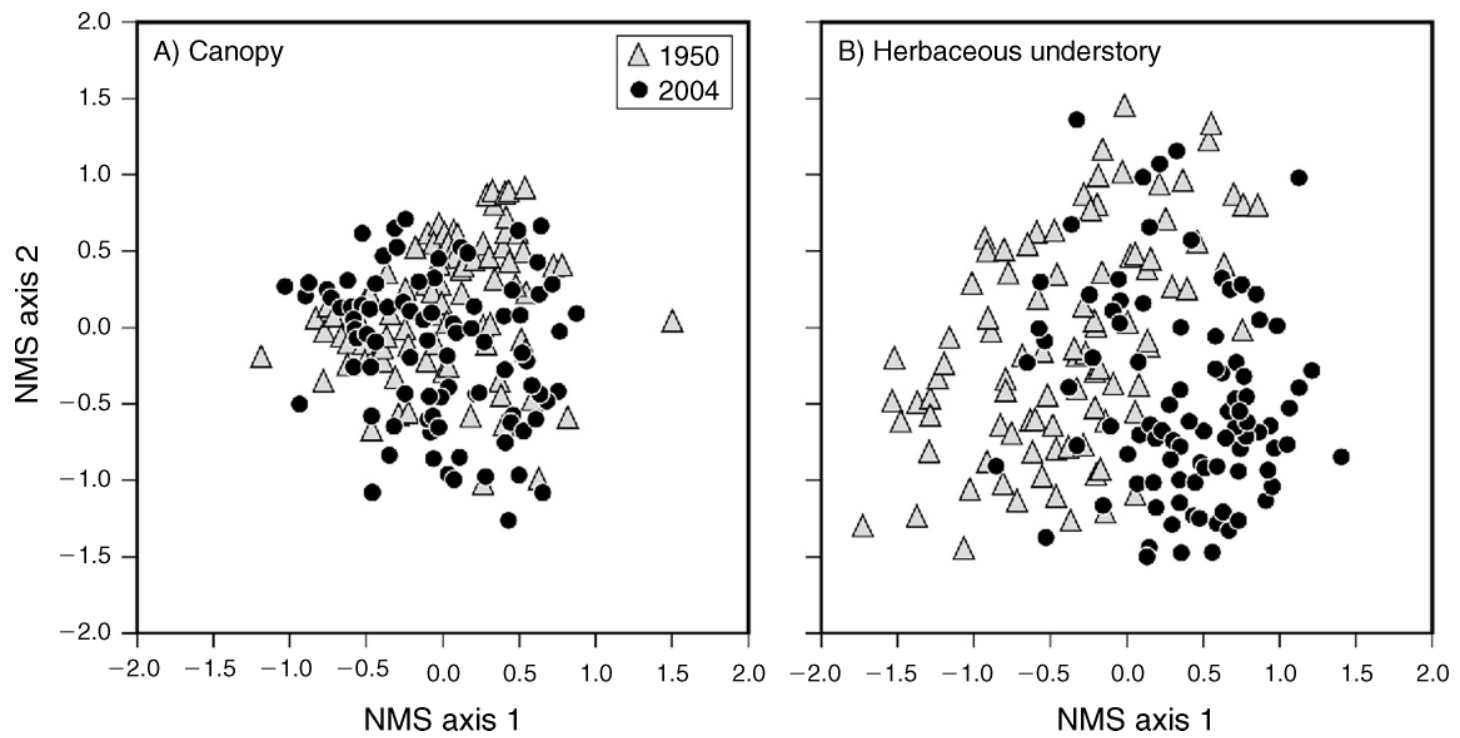

FIG. 4. Combined NMS (nonmetric multi-dimensional scaling) ordinations of 1950 and 2004 samples for (A) canopy species and (B) native understory herbs. See Methods: Analyses.

(13.3\%) in 2004. Exotic species that occupied only 13 stands (14\%) in 1950 occurred at 76 sites $(81 \%)$ in 2004. Their relative abundance within sites increased sevenfold from an average of $1.2 \%$ in 1950 to $8.4 \%$ in 2004 .

Collective native herb, shrub, and woody vine species richness at the $20-\mathrm{m}^{2}$ scale declined at 70 of the 94 sites (75\%). Mean species richness per site declined $23.1 \%$ (from 37.8 species $/ 20 \mathrm{~m}^{2}$ in 1950 to 29.1 species $/ 20 \mathrm{~m}^{2}$ in 2004, paired $t=8.25, P<0.0001)$. On average, sites appeared to lose 18.5 species (48.9\%) while only gaining back 9.8 species. At the $1-\mathrm{m}^{2}$ scale, native species density declined on average $25 \%$ (from 8.5 species $/ \mathrm{m}^{2}$ to 6.4 species $/ \mathrm{m}^{2}$, paired $\left.t=7.30, P<0.0001\right)$. Most of this decline in native understory richness reflected a $27 \%$ decline in native herbaceous species at the $20-\mathrm{m}^{2}$ scale (28.5 vs. 21.3 , paired $t=7.27, P<0.0001$ ). In contrast, the number of native woody species declined by only $11.8 \%$ (9.3 vs. 8.2 species, paired $t=3.39, P=0.001$ ) leading to a $14.7 \%$ increase in the relative abundance of woody species (from 0.185 to 0.217 , paired $t=-3.08, P=$ 0.003 ) in the understory.

The NMDS ordinations reveal clear and consistent shifts in overall community composition for the combined, herbaceous (Fig. 4B), and woody understory communities. Each returned a three-dimensional solution with similar final stress values $(0.15,0.15$, and 0.17 for combined, herbaceous, and woody species, respectively). ANOSIM analyses confirmed that 1950 and 2004 samples differ considerably in species composition (Global $R$ of $0.243,0.262$, and 0.135 , respectively, all $P$ values $<0.001)$. In other words, the forest understories have shown consistent shifts in species composition between the 1950 and 2004 sample periods, and the contemporary vegetation is floristically distinct from the communities that occurred at these same sites in the past.

The sites are converging in native understory community composition, reflecting biotic homogenization. The mean pairwise similarity in understory community composition among stands increased $7.5 \%$ since 1950 (from 30.9 to 33.1, paired $t=-4.10, P<0.001$ ). In contrast to declines in understory species richness, these declines in beta diversity mostly reflect convergence in shrub composition. Shrub similarity increased 18\% among sites (from 0.282 to 0.332 , paired $t=-6.25, P$ $<0.0001)$. Sites that gained shrub species grew more similar in shrub composition over time $(r=0.527, P<$ 0.001). Rates of apparent shrub extirpation or colonization were unrelated to shrub homogenization. In contrast, herb similarity increased only $3.5 \%$ (from 0.314 to 0.325 , paired $t=-2.04, P=0.045$ ). Homogenization in the herb layer was uncorrelated with changes in native herb richness $(r=-0.112, P=0.283)$, rates of apparent extirpation $(r=-0.176, P=0.089)$, or rates of apparent colonization $(r=-0.182, P=0.080)$. Despite these differences, rates of herb and shrub homogenization were correlated $(r=0.316, P=0.002)$, suggesting that similar stand-level processes may drive these trends. SIMPER analyses further support the idea that understories in these stands became more homogenous. In the original sample 38,27 , and 11 species were needed to account for $90 \%$ of the variance in the similarity matrices of the native understory, native herb, and native woody communities, respectively. In 2004, however, only 25,17 , and 7 species explained this same level of variation.

Among the herbs, Circaea lutetiana, Geum canadense, and Arisaema triphyllum increased the most in importance, while Carex spp., Aralia nudicaulis, Galium 
TABLE 1. Spearman rank correlations showing changes in native species richness: relationships between soil factors, initial forest composition, and changes in forest structure and understory dynamics.

\begin{tabular}{|c|c|c|c|c|c|c|}
\hline Variables & Quadrat & Site & Herbs & Shrubs & $\begin{array}{c}\text { Apparent } \\
\text { colonization }\end{array}$ & $\begin{array}{l}\text { Apparent } \\
\text { extirpation }\end{array}$ \\
\hline \multicolumn{7}{|l|}{ Soil variables } \\
\hline Sand (\%) & $0.245 *$ & 0.248* & $0.25 *$ & 0.096 & 0.189 & -0.07 \\
\hline $\mathrm{N}(\%)$ & $-0.206 *$ & -0.162 & -0.113 & -0.136 & -0.148 & 0.075 \\
\hline \multicolumn{7}{|l|}{ Initial forest composition } \\
\hline SI 1950 & $-0.380 * * *$ & $-0.280^{* *}$ & -0.177 & -0.114 & $-0.476 * * *$ & 0.102 \\
\hline Red oaks 1950 & $0.456 * * *$ & $0.326 * * *$ & $0.295^{*}$ & 0.094 & $0.521 * * *$ & -0.136 \\
\hline Richness 1950 & $-0.387 * * *$ & $-0.224 *$ & -0.188 & $-0.261 *$ & 0.178 & -0.014 \\
\hline \multicolumn{7}{|l|}{ Change in forest structure } \\
\hline Change in Avg. BA & -0.179 & -0.13 & -0.072 & -0.244 & $-0.265^{*}$ & 0.059 \\
\hline Change in $\mathrm{BA} / \mathrm{ha}$ & $-0.242 *$ & $-0.267 * *$ & $-0.213 *$ & $-0.295 *$ & $-0.341^{* * *}$ & 0.188 \\
\hline
\end{tabular}

Notes: Only predictors with at least one significant relationship to the response variables are shown. Initial forest composition is represented by stand successional index (SI) in 1950, red oak relative frequency in 1950, and understory species richness in 1950. Changes in overstory composition are represented by changes in average basal area (BA) per tree and BA per hectare. Understory dynamics are represented by changes in native understory species richness at the quadrat $\left(1-\mathrm{m}^{2}\right)$ and site $\left(20-\mathrm{m}^{2}\right)$ scales. "Herb" and "Shrub" refer to the herbaceous and shrub components of overall site $\left(20 \mathrm{~m}^{2}\right)$ species richness. Apparent colonization and extirpation refer to the numbers of native species observed to appear or disappear at a site based on the 20- $\mathrm{m}^{2}$ samples. Values shown are Spearman rank correlations of the various predictor variables to changes in these dependent variables. Numbers in boldface type represent significant relationships.

$* P<0.05 ; * * P<0.01 ; * * * P<0.001$.

concinnum, Desmodium glutinosum, and Amphicarpaea bracteata all showed strong declines in frequency and importance (Appendix B). Most of the important species in the original sample also declined. The woody community has also changed dramatically. Taxa such as Celastrus scandens, Cornus racemosa, and Corylus americana declined greatly, while Parthenocissus spp., Ribes missouriense, and Prunus virginiana increased markedly in abundance. The trailing vine Parthenocissus spp. showed particularly conspicuous increases in relative importance, from $30 \%$ in the original survey to 49\% in 2004 (Appendix C).

\section{Influence of exotic species invasions}

These declines in richness and increases in homogenization in the combined understory community do not appear to be the consequence of exotic species invasions. Across these 94 forests, local declines in understory native species richness were uncorrelated with either the presence or local abundance of exotic taxa (analyses not shown). Including the exotic species in our calculations of average between-stand similarity reduced the increase in mean community similarity from $7.5 \%$ to $2.6 \%$, suggesting that exotic invasion has increased heterogeneity between stands. However, stands with greater exotic species abundance in 2004 also tended to experience more native herb homogenization than less invaded stands $(r=0.286, P=0.005)$, suggesting that the factors that make stands vulnerable to exotic species invasions also contribute to gains of native habitat generalists and losses of habitat specialists.

\section{How do initial conditions affect shifts in composition?}

Early-successional stands (i.e., those with many oaks and low SI values in 1950) experienced the greatest changes over the next 50 years. These stands showed less similarity to their original composition, as evidenced by a positive correlation between stand SI in 1950 and the Bray-Curtis similarity of a stand to itself between samples $(r=0.47, P<0.001)$. They also experienced more successional change, as shown by the negative correlation between stand SI in 1950 and the change in SI $(r=-0.53, P<0.0001)$. In addition, these stands gained more tree species (stand SI in 1950 vs. change in tree richness, $r=-0.57, P<0.001)$ and tended to diverge more in composition (correlation between SI 1950 and change in average similarity to other stands: $r$ $=0.49, P<0.001)$. Soil texture and nutrients were strongly correlated with these initial SI values and thus showed similar patterns. Coarse, nutrient-poor soils tended to gain canopy species and undergo biotic differentiation, while stands on nutrient-rich soils tended to lose canopy species and undergo homogenization. Acer negundo, Acer rubrum, Prunus serotina, and Carya ovata tended to expand most on nutrient-poor soils and early-successional stands, whereas Acer saccharum expanded the most on fine-textured, nutrient-rich soils with high SI values.

A site's initial canopy composition and successional state also affected subsequent changes in understory richness (Table 1). Later successional stands showed greater declines in overall native understory richness than did early-successional stands at both the $1-\mathrm{m}^{2}$ and 20 - $\mathrm{m}^{2}$ scales $(r=-0.38, P<0.001$ and $r=-0.28, P<$ 0.05 , respectively). Stands in 1950 with the most red oak (Q. rubra and Q. velutina) were least likely to lose native understory species, as evidenced by positive correlations between red oak relative frequency in 1950 and rates of change in overall understory species richness at the $1-\mathrm{m}^{2}$ and $20-\mathrm{m}^{2}$ scales $(r=0.46$ and 0.33 , both $P<0.001)$. 
This trend may reflect the fact that sites with a high relative frequency of red oaks also experienced higher apparent rates of native species colonization $(r=0.52, P$ $<0.001)$ with no greater rate of apparent extirpation $(r$ $=-0.136, P=0.192)$. Similarly, stands that increased the most in basal area per hectare experienced greater species losses (Table 1), a trend that may be linked to their lower rates of apparent colonization $(r=-0.26, P=$ $0.01)$ and, to a lesser extent, increased extirpation $(r=$ $0.19, P=0.069$ ).

Understory herbs typical of early-successional oakdominated sites declined more in abundance than those species that typically occur in late-successional or more mesic sites. Although early-successional stands tended to lose fewer species overall, the understory species most tied to these forests (with low SAV values in the original sample) declined more than species with high SAV values, both in terms of the number of sites they occupied and their total frequency $(r=-0.33$ and -0.26 , respectively, $P<0.01$ ). This trend was confined to herbaceous species, as shrub species showed no relationship between their 1950 habitat preference and observed declines.

These forest understories have also lost beta diversity, as shown by increases in the mean similarity among sites. This homogenization appears unlinked to a stand's initial successional state, as evidenced by the lack of any significant correlation between 1950 SI and overall understory mean similarity $(r=0.199, P>0.05)$. Changes in beta diversity in both the herbaceous and woody communities were also unrelated to initial successional index. However, stands on fine-textured, nutrient-rich sites converged more in species composition than those on coarse-textured, nutrient-poor soils (Appendix D). As with declines in alpha diversity, declines in beta diversity (homogenization) in the herb layer were correlated with soil conditions (e.g., percentage of clay, $r=0.34, P<0.001$ and silt, $r=0.23, P<$ $0.05)$. Homogenization in the shrub layer, however, was unrelated to soil variables.

\section{Potential drivers of change}

Canopy species richness in 2004 depended on initial tree richness and initial successional status (SI score in 1950 , both $P<0.001$ ) as well as soil texture (PCA axis 2, $P=0.018)$ with adjusted stepwise regression $R^{2}$ values increasing from $52.1 \%$, to $59.1 \%$, to $61.2 \%$. Changes in average canopy similarity, however, depended only on initial SI and initial average similarity (both $P<0.001$ ), which explained $23.9 \%$ and $17.4 \%$ of the variance, respectively.

Overall changes in understory richness at $1 \mathrm{~m}^{2}$ reflected the original richness present in 1950, initial SI (both $P<0.001$ ), and changes in basal area per hectare $(P=0.023)$, which contributed $15 \%, 14.8 \%$, and $4 \%$, respectively, to the variance explained. The amount of understory homogenization reflected initial average similarity $(P<0.001)$ and soil fertility (PCA 1: $P=$
$0.016)$, but not initial canopy composition $(P=0.416)$. The absence of any strong correlation between initial canopy conditions (1950 SI) and the homogenization observed in the combined, herbaceous, and woody communities may reflect declines in how strongly canopy conditions are affecting the understory generally. Indeed, the correlation between canopy and total understory similarity matrices declined from a robust 0.483 in 1950 to 0.240 by 2004 (both $P<0.0001$ in Mantel randomization tests).

\section{Discussion}

Although previous work has already made clear that oaks have declined in importance in forests across eastern North America (Abrams 2003, Lorimer 2003), we have extended these findings by examining in detail both canopy and understory changes over half a century at a widely dispersed set of sites. Gradual trends of the kind that take decades to manifest are often difficult to discern in ecological data, but the Curtis (1959) baseline data allowed us to lift the veil on this "invisible present" (Magnuson 1990). Canopy and understory richness, composition, and heterogeneity have all shifted significantly, probably in response to both light conditions and the elimination of fires. These trends are not particular to one or a few sites, nor do they reflect dramatic changes at already degraded sites. Rather, they reflect consistent and systematic changes occurring across a widely distributed set of 94 of the best natural habitats that existed at the time of the baseline survey. Thus, these data provide uniquely detailed and statistically robust insights into how these forest understories have changed and are likely to continue to change in the future.

Declines in the dominance of oaks in the overstory accompanied by increases in the dominance of maples, ash, and elm are conspicuous, creating a pattern of "mesification" already noted by others (Shotola et al. 1992, Fralish 2004, Ozier et al. 2006, Spyreas and Matthews 2006, Nowacki and Abrams 2008). Earlysuccessional stands were more likely to recruit new canopy species, likely reflecting increases in fire-intolerant species. The faster declines in the red oaks (Quercus rubra or $Q$. velutina) relative to white oak may reflect either their greater dependence on fires for establishment, or their greater susceptibility to disease (Menges and Loucks 1984). Stands that began with more red oak in the canopy also experienced greater turnover in their understories, usually by being able to recruit new species to replace those lost to canopy succession or other factors.

Understory plant richness and heterogeneity have declined dramatically in these forests, with rates of species loss almost twice those observed in northern Wisconsin (Rooney et al. 2004b). Shadier conditions and increased shrub dominance are likely to further curtail future oak regeneration (Lorimer et al. 1994, Lorimer 2003) and reduce herb density and diversity (Fralish 2004). Continued succession in coming years will likely 
cause these stands to converge further in species composition (Ozier et al. 2006). Local site conditions will modify these trends, with oaks and associated understory species persisting best on sandy, nutrientpoor sites (Peet and Loucks 1977).

Declines in species richness may also reflect the fact that many of the forests we surveyed were originally oak savannas (Cottam 1949). High-quality Wisconsin oak savannas typically contain 16 species $/ \mathrm{m}^{2}$ and 89 species $/ 20 \mathrm{~m}^{2}$ (Leach and Givnish 1999), much greater than the 8.5 species $/ \mathrm{m}^{2}$ and 38 species $/ 20 \mathrm{~m}^{2}$ recorded by the PEL for oak forests in 1950, and the 6.4 species $/ \mathrm{m}^{2}$ and 30 species $20 / \mathrm{m}^{2}$ we tallied in these same oak forests today. In our data set, the few remaining species characteristic of oak savannas (Bray 1958, Curtis 1959, Pruka 1995) present in the 1950 data set largely disappeared, including Amorpha canescens, Aster shortii, and Tradescantia ohiensis. However, severe declines in many typical oak forest understory species (Curtis 1959) such as Carex spp., Aralia nudicaulis, Galium concinnium, Desmodium glutinosa, and Sanicula marilandica suggest more species will likely meet the same fate in coming decades. The especially large declines in narrowleaved (Carex spp. and Galium spp.) or thick-leaved taxa (Desmodium glutinosa) further support the idea that understory conditions have become much shadier today than in 1950s-era forests. To date, these declines in classic oak understory species have not been compensated by colonization of typical mesic understory herbs, such as Sanguinaria canadensis, Trillium grandiflorum, or Caullophyllum thalictroides (Curtis 1959). Instead, these understory species have been replaced by a small set of habitat generalists that have invaded or expanded locally. Circaea lutetiana and Geum canadense typify the former, and share the trait of producing many small, easily dispersed seeds. This suggests that these species are well adapted to anthropogenic disturbance and landscape fragmentation. Arisaema triphyllum has also increased greatly, mirroring the trend observed in northern Wisconsin (Wiegmann and Waller 2006). These increases suggest that deer herbivory may be driving some changes in the understory, as Arisaema is generally avoided by deer.

The frequency and richness of many shrubs and woody vines also declined, but these changes were less pronounced than those observed in forest herbs. Nevertheless, their shifts in composition and heterogeneity were stronger, a pattern resembling what Davison and Forman (1982) observed in New Jersey. Species recognized by Curtis (1959) as characteristic of xeric or early-successional sites like Corylus americana and Cornus racemosa showed profound declines. These have generally been replaced by expanding populations of dry-mesic or midsuccessional (Curtis 1959) species like Prunus virginiana, Parthenocissus spp., and Ribes cynosbati. The shade cast by these woody species on the herbaceous layer has likely contributed to the declines we observed in herbaceous richness, as shrubs and woody vines are often well positioned to exploit light gaps created when canopy trees die (Davison and Forman 1982, McCune and Cottam 1985). Our work further suggests that hyperabundant native species such as Parthenocissus spp. and Prunus virginiana now threaten native understory diversity as much as exotic shrubs like Lonicera $\times$ bella and Rhamnus cathartica. Reducing these species in the understory would likely improve oak regeneration, understory diversity, and floristic quality (Lorimer et al. 1994).

We were surprised to find that sites with more invasive species did not generally experience higher losses of native species richness. The presence of exotic species at an increasing fraction of our sites and quadrats may thus reflect more of a passive symptom than a direct cause of the substantial declines in understory richness we observed. Alternatively, the absence of demonstrated impacts could reflect a time lag between when invasives become established and when their impacts become manifest.

Similar lag effects could also explain the lack of influence of exotics on community homogenization. Although exotic species invasions increase homogenization at the scale of biogeographic provinces (McKinney and Lockwood 1999), this may not hold true at the scale of local communities or in the short term (Stohlgren et al. 2002). A new invading species will initially serve to increase differentiation among stands until it has invaded about half the stands, beyond which invasions act to increase community similarity (Rooney et al. 2007). Most of the exotic species we detected still occupy fewer than half of these sites, meaning they are not yet acting to increase homogenization. Only garlic mustard (Alliaria petiolata) and common dandelion (Taraxacum officinale) are currently widespread enough to increase biotic homogenization in these stands.

Although initial canopy composition and succession have clearly influenced understory richness and heterogeneity, these influences were relatively weak predictors of change. This observation and the strong decline in the correlation between canopy and understory community composition over time (from 0.48 to 0.24 ) suggest that current understory plant communities are responding to forces beyond succession and edaphic gradients. Evidence for an alternative mechanism can be seen by comparing changes in the hilly unglaciated ("driftless") region of southwest Wisconsin to the flatter and more fragmented forests of southeast Wisconsin. Forests in the driftless area had much lower rates of native species loss $\left(-0.18\right.$ vs. -0.43 species $/ y r$ at $1 \mathrm{~m}^{2}, P=0.006$, and -0.12 vs. -0.41 species $/ y r$ at $\left.20 \mathrm{~m}^{2}, P<0.001\right)$, rates of gain in exotic species ( 0.86 vs. $1.45, P=0.001)$, and rates of homogenization (1.89 vs. $2.12, P=0.002)$ than forests in southeast Wisconsin. Roads, development, and fragmentation are all far more prevalent in the southeast glaciated region (Radeloff 2005), likely contributing to weedy plant invasion while limiting the dispersal of many native woodland species (Matlack 2005). 
As these changes continue, we can expect oak forests to decline further in understory diversity as they become more dominated by a shrinking set of shade-tolerant generalists. This trend will inevitably have cascading effects on habitat quantity and quality for a wide variety of plants and animals. To restore upland forest diversity and stimulate oak regeneration in situ would almost certainly require active management, including the use of fire and possibly limits on deer. Fire has been shown to increase the cover and richness of understory species in some oak-dominated forests (Hutchinson 2005). Without such active efforts, it will be difficult to retain, and likely impossible to restore, viable and ecologically functional examples of this disappearing forest type and its associated woodland flora. Fire is not always a viable management option, however, and even restoring fires to these systems may not suffice to reverse these species losses if reduced seed sources and altered litter and soil conditions now limit seedling establishment for light-demanding oak seedlings and understory herbs (Abrams and Scott 1989, Abrams 2005). In such cases, an alternative strategy might be to favor the colonization of some of these forests by native understory plants adapted to mesic late-successional conditions.

\section{ACKNOWLEDGMENTS}

This work would have been impossible without the vision, sampling, and data archiving of John Curtis, Grant Cottam, Robert McIntosh, and Philip Whitford more than 50 years ago. We are indebted to their efforts. Orie Loucks, Jim Habek, and Ed Beals worked on the Vegetation of Wisconsin project and provided crucial insights and details about their efforts. We also thank J. Sulman and D. Kath for their able field skills, and T. Cochrane and $\mathrm{H}$. Iltis of the UW-Herbarium (WIS) for assistance with the plant determinations. Thomas Givnish, Sara Hotchkiss, and Evelyn Howell provided useful comments on versions of the manuscript. Crucial financial support for this project came from both the NSF (DEB grant 0236333) and the USDA NRI-CSREES program (grant 2003-02472).

\section{Literature Cited}

Abrams, M. D. 1992. Fire and the development of oak forests. BioScience 42:346-353.

Abrams, M. D. 2003. Where has all the white oak gone? BioScience 53:927-939.

Abrams, M. D. 2005. Prescribing fire in eastern oak forests: is time running out? Northern Journal of Applied Forestry 22: 190-196.

Abrams, M. D., and G. J. Nowacki. 1992. Historical variation in fire, oak recruitment, and post-logging accelerated succession in central Pennsylvania. Bulletin of the Torrey Botanical Club 119:19-28.

Abrams, M. D., and M. L. Scott. 1989. Disturbance-mediated accelerated succession in two Michigan forest types. Forest Science 35:42-49.

Albert, D. A. 1995. Regional landscape ecosystems of Michigan, Minnesota, and Wisconsin: a working map and classification. USDA Forest Service North Central Forest Experiment Station, St. Paul, Minnesota, USA.

Auclair, A. N., and F. G. Goff. 1971. Diversity relations of upland forests in the western Great Lakes area. American Naturalist 105:499-528.

Bray, J. R. 1958. The distribution of savanna species in relation to light intensity. Canadian Journal of Botany 36:671-681.
Clarke, K. R. 1993. Non-parametric multivariate analyses of changes in community structure. Australian Journal of Ecology 18:117-143.

Cottam, G. 1949. The phytosociology of an oak woods in southwestern Wisconsin. Ecology 30:271-287.

Cottam, G., and J. T. Curtis. 1949. A method for making rapid surveys of woodlands by means of pairs of randomly selected trees. Ecology 30:101-104.

Cottam, G., and J. T. Curtis. 1956. The use of distance measures in phytosociological sampling. Ecology 37:451-460.

Curtis, J. T. 1959. The vegetation of Wisconsin. University of Wisconsin Press, Madison, Wisconsin, USA.

Curtis, J. T., and R. P. McIntosh. 1951. An upland forest continuum in the prairie forest border region of Wisconsin. Ecology 32:476-496.

Davison, S. E., and R. T. T. Forman. 1982. Herb and shrub dynamics in a mature oak forest: a thirty-year study. Bulletin of the Torrey Botanical Club 109:64-73.

Dorney, J. R. 1981. The impact of native Americans on presettlement vegetation in southeastern Wisconsin. Wisconsin Academy of Sciences 69:26-36.

Fralish, J. S. 1997. Community succession, diversity, and disturbance in the central hardwood forest. Pages 234-266 in M. W. Schwartz, editor. Conservation in highly fragmented landscapes. Chapman and Hall, New York, New York, USA.

Fralish, J. S. 2004. The keystone role of oak and hickory in the central hardwood forest. Pages $78-87$ in M. A. Spetich, editor. Upland Oak Ecology Symposium: History, Current Conditions, and Sustainability. USDA Forest Service General Technical Report SRS-373, Southern Research Station, Asheville, North Carolina, USA.

Givnish, T. J. 1987. Comparative studies of leaf form: assessing the relative roles of selective pressures and phylogenetic constraints. New Phytologist 106:131-160.

Gleason, H. A. 1922. The vegetational history of the Middle West. Annals of the Association of American Geographers 12:39-85.

Gleason, H. A., and A. Cronquist. 1991. Manual of vascular plants of northeastern United States and adjacent Canada. Second edition. New York Botanical Garden, New York, New York, USA.

Hutchinson, T. F., R. E. J. Boerner, and S. Sutherland. 2005. Prescribed fire effects on the herbaceous layer of mixed-oak forests. Canadian Journal of Forest Research 35:877-890.

Kline, V. M., and G. Cottam. 1979. Vegetation response to climate and fire in the driftless area of Wisconsin. Ecology 60: 861-868.

Landis, D. A., S. D. Wratten, and G. M. Gurr. 2000. Habitat management to conserve natural enemies of arthropod pests in agriculture. Annual Review of Entomology 45:175-201.

Larsen, J. A. 1953. A study of an invasion by red maple of an oak woods in southern Wisconsin. American Midland Naturalist 49:908-914.

Leach, M. K., and T. J. Givnish. 1996. Ecological determinants of species loss in remnant prairies. Science 273:1555-1558.

Leach, M. K., and T. J. Givnish. 1999. Gradients in the composition, structure, and diversity of remnant oak savannas in southern Wisconsin. Ecological Monographs 69:353-374.

Leitner, L. A., C. P. Dunn, G. R. Guntenspergen, F. Stearns, and D. M. Sharpe. 1991. Effects of site, landscape features, and fire regime on vegetation patterns in presettlement southern Wisconsin. Landscape Ecology 5:203-217.

Lorimer, C. G. 1993. Causes of the oak regeneration problem. Pages 14-39 in D. L. Loftis and C. E. McGee, editors. Oak regeneration: serious problems, practical recommendations. USDA Forest Service, Knoxville, Tennessee, USA.

Lorimer, C. 2003. The decline of oak forests. BioScience 53:915.

Lorimer, C. G., J. W. Chapman, and W. D. Lambert. 1994. Tall understorey vegetation as a factor in the poor development of 
oak seedlings beneath mature stands. Journal of Ecology 82: 227-237.

Loucks, O. L. 1970. Evolution of diversity, efficiency, and community stability. American Zoologist 10:17-25.

Magnuson, J. 1990. Long term research and the invisible present. BioScience 40:495-501.

Matlack, G. R. 2005. Slow plants in a fast forest: local dispersal as a predictor of species frequencies in a dynamic landscape. Journal of Ecology 93:50-59.

McCune, B., and G. Cottam. 1985. The successional status of a southern Wisconsin oak woods. Ecology 66:1270-1278.

McCune, B., and J. B. Grace. 2002. Analysis of ecological communities. MjM Software, Gleneden Beach, Oregon, USA.

McIntosh, R. P. 1957. The York Woods: a case history of forest succession in southern Wisconsin. Ecology 38:29-37.

McKinney, M. L., and J. L. Lockwood. 1999. Biotic homogenization: a few winners replacing many losers in the next mass extinction. Trends in Ecology and Evolution 14: $450-453$.

Menges, E. S., and O. L. Loucks. 1984. Modeling a diseasecaused patch disturbance: oak wilt in the midwestern United States. Ecology 65:487-498.

Milbauer, M. L., and M. K. Leach. 2007. Influence of species pool, fire history, and woody canopy on plant species density and composition in tallgrass prairie. Journal of the Torrey Botanical Society 134:53-62.

Nowacki, G. J., and M. D. Abrams. 2008. The demise of fire and "mesophication" of the eastern United States. BioScience 58:123-138.

Olden, J. D., and N. L. Poff. 2003. Toward a mechanistic understanding and prediction of biotic homogenization. American Naturalist 162:442-460.

Osenberg, C. W., O. Sarnelle, and S. D. Cooper. 1997. Effect size in ecological experiments: the application of biological models in meta-analysis. American Naturalist 150:798-812.

Ozier, T. P., J. W. Groniger, and C. M. Ruffner. 2006. Community composition and structural changes in a managed Illinois Ozark Hills forest. American Midland Naturalist 155:253-269.

Peet, R., and O. L. Loucks. 1977. A gradient analysis of southern Wisconsin forests. Ecology 58:485-499.

Pruka, B. 1995. Lists indicate recoverable oak savannas and open oak woodlands in southern Wisconsin. Restoration and Management Notes 13:124-126.

Radeloff, V. C., R. B. Hammer, and S. I. Stewart. 2005. Rural and suburban sprawl in the U.S. Midwest from 1940 to 2000 and its relation to forest fragmentation. Conservation Biology 19:793-805.
Reid, A. 1964. Light intensity and herb growth in white oak forests. Ecology 45:396-398.

Rentch, J. S., and R. R. Hicks. 2005. Changes in presettlement forest composition for five areas in the central hardwood forest, 1784-1990. Natural Areas Journal 25:228-238.

Rogers, D. A. 2006. Fifty years of change in southern Wisconsin forests: patterns of species loss and homogenization. Dissertation. University of Wisconsin-Madison, Madison, Wisconsin, USA.

Rooney, T. P., J. D. Olden, M. K. Leach, and D. A. Rogers. 2007. Biotic homogenization and conservation prioritization. Biological Conservation 134:447-450.

Rooney, T. P., D. A. Rogers, S. M. Wiegmann, and D. M. Waller. 2004a. Monitoring non-native plant invasions over 50 years in Wisconsin forests. Weed Technology 18:12661268.

Rooney, T. P., S. M. Wiegmann, D. A. Rogers, and D. M. Waller. 2004b. Biotic impoverishment and homogenization in unfragmented forest understory communities. Conservation Biology 18:787-798.

Sharpe, D. M., G. R. Guntenspergen, C. P. Dunn, L. A. Leitner, and F. Stearns. 1987. Vegetation dynamics in a southern Wisconsin agricultural landscape. Pages 137-155 in M. G. Turner, editor. Landscape heterogeneity and disturbance. Springer-Verlag, New York, New York, USA.

Shotola, S. J., G. T. Weaver, P. A. Robertson, and W. C. Ashby. 1992. Sugar maple invasion of an old-growth oakhickory forest in Southwestern Illinois. American Midland Naturalist 127:125-138.

Spyreas, G., and J. W. Matthews. 2006. Floristic conservation value, nested understory floras, and the development of second-growth forest. Ecological Applications 16:1351-1366.

Stohlgren, T. J., G. W. Chong, L. D. Schell, K. A. Rimar, Y. Otsuki, M. Lee, M. A. Kalkahan, and C. A. Villa. 2002. Assessing vulnerability to invasion by nonnative plant species at multiple spatial scales. Environmental Management 29: 566-577.

Van Breemen, N., and A. C. Finzi. 1998. Plant-soil interactions: ecological aspects and evolutionary implications. Biogeochemistry 42:1-19.

Westerkamp, C., and G. Gottsberger. 2000. Diversity pays in crop pollination. Crop Science 40:1209-1222.

Whitford, P. B., and P. J. Salamun. 1954. An upland forest survey of the Milwaukee area. Ecology 35:533-540.

Wiegmann, S. M., and D. M. Waller. 2006. Biotic homogenization in forest understories: identity and traits of historical "winners" and "losers." Biological Conservation 129:109123.

\section{APPENDIX A}

A table showing importance values of canopy species for the "average" stand and the total frequency in each time period (Ecological Archives E089-139-A1).

\section{APPENDIX B}

A table showing changes in the importance values and total frequency of individual species in each time period for herbaceous species (Ecological Archives E089-139-A2).

\section{APPENDIX C}

A table showing changes in contribution within group similarity for the top native woody taxa in either time period (Ecological Archives E089-139-A3).

\section{APPENDIX D}

A table showing influence of initial successional state and soil variables on rates of community homogenization for the understory as a whole, for the herbaceous community, and for the woody community (Ecological Archives E089-139-A4). 